\title{
Social Protection, the Millennium Development Goals and Human Rights
}

\author{
Wouter van Ginneken*
}

\begin{abstract}
This article is an attempt to outline the possible implications of a rights-based approach to social protection and the Millennium Development Goals (MDGs). It starts with some remarks on the role of social protection floors and human rights in a new global social contract. It then provides a framework as to how the rights-based approach can be operationalised - for four main human rights principles and using structural, process and output indicators. It applies this framework to the right to social security. The penultimate section shows that the adoption of national social protection floors would constitute a key ingredient to a human rights approach towards achieving the MDGs before and after 2015. It also points out the potential role of the UN Human Rights Council in monitoring MDGs in the future.
\end{abstract}

\section{Introduction}

The adoption of the Millennium Development Goals (MDGs) marks the first time in history that the world community has accepted to be accountable for the achievement of global objectives. The MDGs can be considered a first 'claim' of the poor towards global society and a first component of a global social contract. This claim is legitimate because the social dimension of globalisation requires that everyone is entitled to some of the benefits produced (ILO 2004). This claim can also be economically realised, because the global economy produces huge benefits, which are distributed very unequally both between and within countries.

The human rights approach reinforces this aspect of claims and entitlements. Almost all countries in the world have ratified the basic human rights treaties, including civil and political, as well as economic, social and cultural rights. While in earlier years the emphasis was on civil and political rights, there is now increasing awareness that the human rights approach can also be implemented for economic, social and cultural rights.

Social protection has become a centrepiece for development, because it is an indispensable ingredient for empowering people to participate in society in all its dimensions - social, political, economic and cultural. It is also increasingly considered as an essential tool for states to fulfil their human rights obligations. These are some of the basic ideas behind the social protection floor (SPF) that is defined as a set of guarantees that secure the availability and provision of, and access to, an essential level of quality social protection and services to all (UNDP-ILO 2010).

This article is an attempt to outline the possible implications of a rights-based approach to social protection and the MDGs in general. It starts with some remarks on the role of social protection and human rights in a new global social contract. It will then give some examples as to how the rightsbased approach can be operationalised - for the four main human rights principles and using structural, process and output indicators. The penultimate section will show how this approach can help in better attaining the MDGs before 2015, and how it could help in defining the approach towards MDGs after 2015. In addition, it will point out the potential role of the UN Human Rights Council in monitoring MDGs in the future. The article ends with some concluding remarks in the final section.

\section{Social protection and human rights in a new global social contract}

The SPF could be considered as part of a new global contract, in that it guarantees that all 
workers and citizens have the capacity to participate in economic, social, political and cultural life. Social protection is particularly important for vulnerable people who have little or no access to services and transfers. Social protection is not just a residual safety net, but is one of the building blocks for a peaceful society in which economic and social development can flourish. It can also contribute over the longer run to more just and equitable social outcomes.

Human rights are 'basic moral guarantees that people in all countries and cultures allegedly have simply because they are people' (Fagan 2006). These are global values that go beyond considerations of strict national sovereignty. Calling these guarantees 'rights' means that each individual can invoke them, that they are of high priority, and that compliance is mandatory rather than discretionary. Even though almost all countries in the world have ratified the seven basic human rights treaties, in many countries the development of moral rights has not yet been concretised as legal rights in national legislation. Human rights, and in particular economic and social rights, become claimable and operational when they are recognised as legal rights.

The rights granted under the human rights instruments generate a number of obligations for states. Depending on the level of economic and social development, the International Covenant of Economic, Social and Cultural Rights (ICESCR) allows countries the 'progressive realisation' of the rights conferred by the Covenant, but they cannot use this article 2 as a pretext for non-compliance. Member states have therefore some flexibility in the way they can implement the provisions of the Covenant, but it does impose a strict obligation of the gradual realisation of the respective rights. In addition, every state party to the Covenant has a basic obligation to ensure a minimum level of enjoyment of every right. According to the Commission on Economic, Social and Cultural Rights (CESC), the minimum core content of each right constitutes a floor below which conditions should not be permitted to fall in any state party.

Social protection programmes and the adoption of national SPFs can assist states in fulfilling their obligations under international human rights law, such as with regard to the right to an adequate standard of living, including food, clothing and housing and the right to social security. They may also facilitate the realisation of many other rights, such as the right to education and the right to the highest attainable standard of health, as well as the right to take part in the conduct of public affairs. These legally binding obligations refer to the final outcome as well as to the process that is used. Social protection programmes should therefore not only increase the enjoyment of key human rights by their beneficiaries, but also avoid any violation of human rights in their implementation (Sepúlveda 2011).

The underlying structural, social and political drivers of poverty, vulnerability and inequality have to be addressed in the context of a broad development strategy, in which social protection plays an important part. Social protection, such as cash transfers, can have an important direct impact on the reduction of poverty. However, the impact of such transfers on inequality may depend on the way these transfers are financed by progressive income and wealth taxes or by more regressive taxes on products and services. On the other hand, by providing the equal distribution of basic capabilities for all to participate in society, social protection can set the stage for policies that promote equality and fair distribution. Finally, it can contribute to key societal goals, such as employment, health and durable development - through the appropriate design and implementation of social protection policies and programmes.

\section{Operationalising the rights-based approach}

While the state is the principal duty-bearer with respect to the human rights of the people living within its jurisdiction, all major social, economic, political and cultural groups in society have a shared responsibility for the achievement of human rights enjoyment for everyone. The international community at large also has a responsibility to help realise universal human rights. Thus, monitoring and accountability procedures should extend to global actors - such as the donor community and international NGOs; intergovernmental organisations, such as the United Nations and various regional organisations; as well as transnational corporations (van Ginneken 2010).

In order to operationalise the rights-based approach, it is necessary to develop a conceptual framework that is aimed at measuring the accountability of the various actors. Part of this 
framework consists of four main human rights principles that need to be respected in the implementation of all human rights (see below). Moreover, there is the need to define for each right a few characteristics and a corresponding configuration of structural, process and outcome indicators. The structural and process indicators measure the effort of duty-bearers to achieve the outcome indicator - which is the enjoyment of human rights. We later illustrate the application of this framework to the right to social security.

\subsection{Four main human rights principles}

When designing, implementing, monitoring and evaluating social protection (and other development) programmes, states must ensure compliance with four main human rights principles (Sepúlveda 2011): (1) equality and nondiscrimination; (2) participation; (3) transparency and access to information; and (4) accountability.

Respecting the principle of equality and nondiscrimination means first of all that nobody should be unfairly excluded. Targeted schemes can be accepted as a form of prioritisation of the most vulnerable and disadvantaged groups within a longer-term strategy of progressively ensuring universal protection. Two issues are of particular relevance here: (a) that exclusion errors are minimised, and (b) that failure to comply with conditionalities or co-responsibilities is not used for punishing the beneficiaries, but to provide them with services that correspond with their needs.

Implementing the principle of equality and nondiscrimination means that all services and benefits are accessible and available geographically and financially. There are many specific obstacles to the accessibility of services related to the conditions of particular groups, such as the elderly, persons with disabilities and women. States should, of course, first facilitate access to certain types of administrative requirements, such as ID registration and registration at birth. They must also remove administrative barriers that prevent people from accessing social protection, such as requiring identification documents for registration when such documents are costly or may not exist.

The participation of people from vulnerable groups in legislation, policies and programmes that affect them is a key condition for successful social protection programmes. This participation can create a better understanding with professionals and institutions, and therefore make these programmes more effective. The ultimate stage of the participation process is the monitoring and assessment of the success or failure of these strategies and policies, so that the state and other duty-bearers can be held accountable for their obligations. This process should be an ongoing cycle so that the solutions that are proposed and put in place can be constantly evaluated with those whom they are designed to benefit. Appropriate institutional arrangements are needed for such participation to be possible (van Ginneken 2010).

Transparency and access to information are essential elements of accountability. States must implement programmes in a manner that allows individuals to easily recognise and understand: (i) the eligibility criteria; (ii) the specific benefits they will receive, and (iii) the existence and nature of complaints and redress mechanisms. When accountability and redress mechanisms are in place, social protection programmes are more likely to avoid stigma, because they will be understood in terms of entitlements and rights.

\subsection{Structural, process and output indicators}

To make human rights policies operational, it is necessary to define indicators that can measure the realisation of human rights, such as through measures of social protection coverage. Many human rights indicators are standard indicators of socioeconomic progress, but some - especially those relating to civil and political rights - do not usually figure in measures of socioeconomic progress. Essentially, what distinguishes a human rights indicator from a standard disaggregated indicator of socioeconomic progress is less its substance than (a) its explicit derivation from a human rights norm and (b) the purpose to which it is put, namely human rights monitoring with a view to holding duty-bearers to account.

The Office of the High Commissioner for Human Rights (OHCHR)has started to develop a framework of human rights indicators (OHCHR 2008). The first task is to translate the narrative on the normative content of human rights (based on related provisions of international human rights instruments and general comments by treaty bodies) into a few (four to five) characteristic attributes. Moreover, there is a 
Table 1 List of illustrative indicators on the right to social security

\begin{tabular}{lll}
\hline $\begin{array}{l}\text { Income security for } \\
\text { workers }\end{array}$ & $\begin{array}{l}\text { Affordable access to health } \\
\text { services, including health } \\
\text { insurance }(\mathrm{HI})\end{array}$ & $\begin{array}{l}\text { Support for families, } \\
\text { children and dependant schemes } \\
\text { adults (in cash and in kind) }\end{array}$ \\
\hline
\end{tabular}

Structural Date of entry into force and coverage of the right to social security in the Constitution, other forms of superior law and domestic laws

Timeframe and coverage of policy or strategy for universal implementation of right to social security

Process Proportion of received complaints on the right to social security investigated, adjudicated and acted upon by the government

Number of workers Persons contributing to $\mathrm{HI}$ Public expenditure on

registered

Benefits requested and Incidence of co-payments Percentage of support

provided

support measures

Density of offices

providing $\mathrm{SA}$

in $\mathrm{h} / \mathrm{h}$ income

$\mathrm{SA}$ requests reviewed

and met

Outcome Benefits received

Coverage by $\mathrm{HI}$ schemes

Percentage of families

Population in need

Affordable access to health receiving support

care

receiving specific $\mathrm{SA}$

support

Proportion of individuals below national poverty line before and after social transfers

Source Adapted from OHCHR (2008).

need for a conceptual framework, which explains the impact of the various input indicators on the eventual outcome - the enjoyment of human rights. 'Structural' indicators measure the commitment of the state (the main duty-bearer) towards realising human rights, such as through ratification of international instruments and inclusion in national legislation, as well as through the adoption of national policies and corresponding timeframe. 'Process' indicators measure the efforts and resources that the dutybearer uses to achieve the enjoyment of human rights, which is measured by 'outcome' indicators.

\subsection{The example of the right to social security}

The right to social security is fundamental to the realisation of social protection for all. The four characteristic attributes for the right to social security are: 'income security for workers'; 'affordable access to health services'; 'support for families, children and dependant adults' and 'social assistance schemes' (Table 1). While the characteristic attributes shown in Table 1 have universal application, this is not the case for all structural, process and outcome indicators presented in the table.

The structural indicators in Table 1 have a universal aspect, because they are generally part of national and international legislation. However, the way the right to social security is included in that legislation will be particular to the country concerned. The process indicators also have a universal aspect, but much depends on the level of economic and social development, as to how much inputs and resources are needed to achieve universal coverage and at what level of benefits. Finally, the outcome indicators are generally country-specific. The definition of the national poverty line, for example, depends on the level of the country's economic developments and its social priorities.

\section{The human rights-based approach towards MDGs before and after 2015}

The MDGs are time-bound development targets that address many dimensions of poverty, such as hunger, disease, inadequate water supplies and lack of education. However, as brought out by the International Labour Office (ILO 2010), there is little hope for these targets to be achieved without a decisive global move towards introducing national SPFs. ${ }^{1}$ These targets are similar to human rights indicators, and this section will therefore examine how a rightsbased approach could help in better achieving MDGs before and after 2015 (van Ginneken 2009). This section will also examine the potential role of the UN Human Rights Council in monitoring MDGs.

\subsection{The situation before 2015}

By the year 2010, there had been good progress with regard to a number of MDGs. The objective 
of halving the number of people living in extreme income poverty between 1990 and 2015 is likely to be achieved, mainly through the good results in China and South Asia. The Millennium Goals Report (UN 2010a) also mentions big gains in getting children into primary schools in many low-income countries, particularly in subSaharan Africa, as well as strong interventions in addressing AIDS, malaria and child health and a good chance of reaching the target for clean drinking water. But it also mentions that a variety of disadvantages that hurt the poorest, those living in remote areas or with a disability, or those who are marginalised due to ethnicity or gender, has sapped progress on many other fronts. However, a number of countries, such as Brazil, India and Rwanda, have successfully introduced elements of national SPFs (UNDPILO 2010).

The MDG agenda has been criticised from a human rights point of view, for example for not sufficiently focusing on the poorest of the poor. MDG target 1 focuses on halving extreme poverty, while from a human rights point of view, any person who lives in extreme poverty represents a violation of human rights. Another criticism refers to the absence of social security and social protection in the MDG targets (ILO 2010; Langford 2010). Moreover, a number of MDG targets are not consistent with human rights and provide potentially lower protection. For example, MDG target 2 ignores the crucial requirement of free primary education, which is an immediate obligation in international human rights treaties, and which cannot be postponed to 2015. Other concerns include the lack of effective accountability mechanisms for the MDGs, particularly for donor countries (UN 2008).

Nevertheless, the content of the MDGs partly covers some economic and social rights, and both provide tools to hold governments accountable. They can also reinforce each other, since MDGs potentially provide benchmarks for economic and social rights. In addition, human rights strategies can offer enhanced legitimacy, equity and sustainability to the types of policies needed to achieve the MDGs. Even though the breadth of economic and social rights is enormous, the strength of the MDG approach is that it focuses on a limited set of indicators. According to Vandemoortele (2011), this approach should be continued after 2015.

\subsection{Perspectives for after 2015}

There are various advantages to defining the MDGs for the period after 2015 in the context of a human rights framework. Human rights cover many dimensions of society and therefore contribute to a holistic approach to eradicating poverty and promoting development (Sepúlveda 2011). Human rights standards may also assist in building social consensus and mobilising political commitments at the national, regional and international levels. The human rights approach also focuses on holding governments and other actors accountable for their actions, and by so doing promotes a more efficient use of resources (by promoting access to information and fighting corruption). Lastly, a human rights approach promotes and enhances the empowerment of those living in poverty, thus enabling them to fully assume their responsibilities within their families, communities and societies.

The challenge is therefore to define a limited number of outcome indicators that measure the enjoyment of some key human rights. Among the 60 official MDG indicators, about half could be considered outcome indicators, mainly related to targets 1 to 7 . Some human rights, such as the right to social security, as well as key human rights principles (such as equality, participation, transparency and accountability) also need to be operationalised with outcome indicators. It will then be up to individual states and other actors to develop coherent plans of action that also include structural and process indicators. In defining the outcome indicators, it would be good to make use of the so-called 'Guiding Principles on Extreme Poverty and Human Rights', which are presently being elaborated on by the UN Human Rights Council, and are to be adopted in 2012 (UN 2010b).

In the author's view, the international political context for the adoption of the next (and probably last) round of MDGs is changing. One factor is that many previously low-income countries have become middle-income countries, which have the resources to achieve the realisation of MDGs through a human rights approach. And many presently low-income countries will hopefully be able to achieve that over a period of 10-15 years after 2015. The new global contract would then consist of: (1) new global contracts on trade, migration and the environment; (2) progressively diminishing 
financial support from high-income countries; and (3) a commitment by middle-income countries to provide technical advice to lowincome countries for the realisation of the MDGs. All this would be feasible on the understanding that by 2025 or 2030 , all presently low-income countries would be able to finance, manage and achieve the realisation of the new round of MDGs.

\subsection{The potential role of the UN Human Rights Council \\ Monitoring and accountability require development outcome indicators, but also indicators that individuals or groups of individuals can use to claim their basic human rights. One possible step forward in this process is the adoption in 2008 of the so-called Optional Protocol to the ICESCR. This Protocol has so far been signed by 36 states, and ratified by three states; ten ratifications are necessary for the Protocol to be in force. The Protocol recognises the competence of the ICESCR to receive communications from individuals or groups of individuals; from states; and through the so- called enquiry procedure.}

The Protocol confirms that economic and social rights are 'justiciable'. Various indicators can be identified that reflect not only the scope and recourse to judicial remedy, but also the potential role of non-judicial (administrative), judicial and quasi-judicial (e.g. national human rights institutions) actors in implementing human rights (OHCHR 2006). However, states that have serious problems with their social rights obligations are likely not to accept these procedures. Nevertheless, when in force the Protocol will produce a number of indirect advantages. The greatest advantage is that the ICESCR can then develop a case law, thus helping to interpret the Covenant and supplementing the work under the state reporting procedure. The Optional Procedure also underlines the position that every single right in the Covenant contains some justiciable elements that are capable of being directly applied (Riedel 2007); and it could lead to the development of national judicial procedures. Finally, it provides an important forum for victims, and lends support for national, regional and international initiatives, such as MDGs, to improve the implementation of economic, social and cultural rights.

Every country that has ratified the ICESCR has the obligation to provide a report every five years on the realisation of these rights. Such a report can have a galvanising impact on discussions within that country as to how to improve the fulfilment of economic, social and cultural rights. It would also be most useful if this reporting were included in the Universal Periodical Reviews (UPR), in which every member country of the UN Human Rights Council is held to participate every four years. Both reporting procedures could be used for monitoring the implementation of MDGs, if they were to be defined and implemented in a human rights framework.

\section{Concluding remarks}

This article has focused on the role of social protection, the SPF and the MDGs in creating a new global contract between high-, middle- and low-income countries, as well as between national governments and their citizens. Our global economy has created many benefits which are very unequally distributed, both between and within countries. While a variety of aspects of the global economy need to be reformed, such as through the introduction of a financial transaction tax, the social and political sustainability of our global society and economy will need to be supported by a greater emphasis on human rights. A human rights perspective ensures that all inhabitants of our planet will share in the benefits of globalisation.

The underlying structural, social and political drivers of poverty, vulnerability and inequality have to be addressed in the context of a broad development strategy, in which social protection plays an important part. By providing the equal distribution of basic capabilities for all to participate in society, social protection can set the stage for policies that promote equality and fair distribution. It can also contribute to key societal goals, such as employment, health and durable development - through appropriate design and implementation of social protection policies and programmes.

Social protection programmes are tools that can help states in fulfilling their obligations under international human rights law, with regard to specific rights, such as to health, social security, housing, food and education, but also to the way they realise social protection (and other development) programmes. There are four main human rights principles that should guide the design, implementation, monitoring and 
evaluation of these programmes: (1) equality and non-discrimination; (2) participation;

(3) transparency and access to information and

(4) accountability.

This article pleads for the adoption of national SPFs as a key ingredient to a human rights approach towards achieving the MDGs before and after 2015. The main challenge for the MDGs after 2015 is to continue to define them in terms of a limited number of outcome indicators

\section{Notes}

* Many thanks to Markus Kaltenborn, Janet Nelson and Rachel Sabates-Wheeler for their most helpful comments.

1 In June 2011 the International Labour Conference made a commitment to establish

\section{References}

Fagan, A. (2006) Human Rights, Internet Encyclopedia of Philosophy, www.iep.utm.edu/ h/hum-rts.htm (accessed 27 July 2011)

ILO (2010) World Social Security Report 2010-2011, Geneva: International Labour Office

ILO (2004) A Fair Globalization: Creating Opportunities for All, Report of the World Commission on the Social Dimension of Globalization, Geneva: International Labour Office

Langford, M. (2010) 'A Poverty of Rights: Six Ways to Fix the MDGs', IDS Bulletin 41.1: 83-91

OHCHR (2008) Report on Indicators for Promoting and Monitoring the Implementation of Human Rights, International Human Rights Instruments HRI/MC/2008/3, Office of the United Nations High Commissioner for Human Rights, www2.ohchr.org/english/bodies/icm-mc/docs/ HRI.MC.2008.3EN.pdf (accessed 27 July 2011)

OHCHR (2006) Principles and Guidelines for a Human Rights Approach to Poverty Reduction Strategies $H R / P U B / 06 / 12$, Office of the United Nations High Commissioner for Human Rights, www.unhcr.org/refworld/docid/46ceaef92.html (accessed 27 July 2011)

Riedel, E. (2007) 'Monitoring the 1966 International Covenant of Economic, Social and Cultural Rights', in G. Politakis (ed.), Protecting Labour Rights as Human Rights: Present and Future of International Supervision, Geneva: International Labour Office that measure the enjoyment of key human rights. Some human rights, such as the right to social security, as well as four key human rights principles (equality, participation, transparency and accountability) need to be operationalised with outcome indicators. It will then be up to individual states and other actors to develop coherent plans of action. The use of structural and process indicators, which have been examined in this article, will contribute to making these plans more effective.

national SPFs and to adopt a formal recommendation to this effect during its next session in 2012.

Sepúlveda, M. (2011) Note of the UN Independent Expert on the Question of Human Rights and Extreme Poverty, 49th Session, 11 February, Geneva: Commission on Social Development UN (2010a) The Millennium Development Goals Report 2010, New York: United Nations

UN (2010b) Report of the Independent Experts on the Question of Human Rights and Extreme Poverty, Magdalena Sepúlveda Carmona, on the Draft Guiding Principles on Extreme Poverty and Human Rights A/HCR/15/41, Geneva: Human Rights Council 15th Session

UN (2008) Claiming the Millennium Development Goals: A Human Rights Approach, New York and Geneva: Office of the High Commissioner for Human Rights

UNDP-ILO (2010) Successful Social Protection Floor Experiences, Sharing Innovative Experiences 18, New York: United Nations Development Programme (UNDP)

van Ginneken, W. (2010) 'A Rights-based Approach to Poverty Eradication in Europe', paper presented to the 8th ESPAnet Conference, Budapest, 2-4 September van Ginneken, W. (2009) 'Social Security and the Global Socio-economic Floor: Towards a Human Rights-based Approach', Global Social Policy 9.2: 228-45

Vandemoortele, J. (2011) 'If not the Millennium Development Goals, Then What?', Third World Quarterly 32.1: 9-25 